\title{
Modelling the lifetime of banknotes with a semi-Markov chain model
}

\author{
Emily Loizidou ${ }^{\mathrm{a}}$ Simon Jones ${ }^{\mathrm{b}}$ Emma Grey ${ }^{\mathrm{b}}$ Mee Chi SO ${ }^{\mathrm{c}}$ \\ ${ }^{a}$ CORMSIS/School of Mathematics, University of Southampton, Southampton, Hampshire, \\ United Kingdom, SO17 1BJ; b De La Rue Analytics, De La Rue House, Jays Close, Viables, \\ Basingstoke, Hampshire, United Kingdom, RG22 4BS; ${ }^{\mathrm{c}}$ CORMSIS/Southampton Business \\ School, University of Southampton, Southampton, Hampshire, United Kingdom, SO17 1BJ
}

\section{ARTICLE HISTORY}

Compiled November 13, 2020

\begin{abstract}
The quality of banknotes in circulation is important for cash cycles. Central banks continuously try to find new methods for improving the quality of banknotes in circulation, whether by improving the specification of the banknotes or the characteristics of the cash cycle. The way that banknotes deteriorate and the speed with which they do so are some of the main factors affecting the quality of banknotes in circulation and thus, have been drawing the interest of central banks. This study develops a new semi-Markov chain model that could be used by banknote printing companies and central banks to model banknote deterioration. Discrete states of fitness are used in this semi-Markov model to simulate how the banknotes transit between fitness levels. The model requires some input parameters to simulate the cash cycle and present the probability distributions for each state. It is applied to theoretical cash cycles and a sensitivity analysis is performed to identify the parameters that have the greatest impact on the quality of banknotes. This study is the first to apply a semi-Markov model to estimate the lifetime of banknotes. It can be used as a forecasting tool for the proportion of unfit banknotes in circulation.
\end{abstract}

\section{KEYWORDS}

Banking; Simulation; Semi-Markov model; Banknotes; Ageing

\section{Introduction}

Despite the rapid increase in the use of electronic payment methods such as debit/credit cards, contactless payments, mobile payments, and digital currencies, banknotes are still used by millions of people daily around the world, and the total value of cash in circulation keeps increasing each year. The United Nations Treasury recognises more than 150 currencies (United Nationals-Treasury, 2019) and each currency has a number of denominations with different designs, colours, and security features. There has been a substantial increase in the number of banknotes in circulation, from about 200 billion in 2004 to 600 billion today (DLR Analytics, 2018). Figure 1 shows the growth of the value in circulation for China, Euro area countries, Australia, and the UK ${ }^{1}$. In most countries, the volumes of banknotes exhibit seasonality trends,

\footnotetext{
Corresponding author: M.C.SO Email: m.so@soton.ac.uk

${ }^{1}$ The data used for plotting the graphs of Figure 1 are downloaded from the International Monetary Fund (http://data.imf.org/) and European Central Bank (ECB) Statistical data warehouse (https://sdw.ecb. europa.eu/).
} 
including weekly and monthly patterns. The number of banknotes in some countries increases just before the weekend and towards the end of the month because of payments to employees. Different countries have different calendar effects but many of them experience an increase in banknotes in circulation during summer, and before the holiday periods of Christmas and Easter (Cabrero et al., 2009). In China, there is a seasonality effect during the Chinese New Year, one of the country's most important festivals for which people traditionally hand out red envelopes as gifts containing cash. Other factors that affect the volume of cash in circulation include inflation rates and gross domestic product (GDP). When inflation rates increase, prices of products increase and thus, the public needs more cash when completing transactions, leading to a higher volume of cash in circulation. Similarly, there is a strong positive correlation between cash in circulation and GDP. The more goods and services a nation produces, the higher the economic activity and thus, the more cash in circulation.

\section{[Figure 1 about here]}

During their lifetime, banknotes exchange hands and are involved in a variety of transactions. The more a banknote is used by the public, the more it deteriorates, reaching a point at which it is no longer suitable for circulation. The reason that users rarely come across completely unusable banknotes is because banknotes are frequently returned to facilities at which sorting machines perform quality checks to determine their fitness level. Banknotes are inspected, and those deemed unfit (around 150 billion banknotes per year) are then destroyed and replaced by new ones (Lepecq, 2016). The security, quality, and availability of banknotes in circulation are crucial factors for the smooth running of a country's economy. Thus, Central banks (CBs) need to ensure that all three characteristics meet the public's expectations and demands.

The average lifespan of banknotes varies considerably around the world, even though all denominations are made with the same materials in most countries. This is due to a variety of factors, including different weather conditions (e.g. high temperatures and humidity) and the way in which people handle banknotes. Higher denominations are more likely to be used as a store of value and thus, deteriorate at a lower rate. Table 1 shows the average lifetime of US banknotes as of 2013 for the first five denominations and as of 2012 for a US $\$ 100$ banknote $^{2}$ (Federal Reserve Bank, 2017). According to the Federal Reserve, about $55 \%$ of transactions under US $\$ 10$ are made with cash compared to $15 \%$ for transactions between US $\$ 50$ and US $\$ 99$ (OBrien, 2017). This suggests that US $\$ 1$, US $\$ 5$, and US $\$ 10$ banknotes are more likely to be used for cash payments and for change, which is the reason for their different lifespans to higher denominations.

[Table 1 about here]

The lifecycle of banknotes consists of several steps, beginning at the factory where they are produced and ending at CBs where they are destroyed. Depending on the individual country's policies, there are different types of banknote supply chains in the world (Geismar et al., 2016). Different types of supply chains result in having different parties (e.g. CBs, commerical banks, private organisations) to handles banknote services (e.g. sorting, circulating). As this paper is inspired by the work of Deinhammer \& Ladi (2017), the banknote lifecycle described here provides an overview of a typical Euro area's cash cycle. It is thus worth to note that the cash cycle introduced in the

${ }^{2}$ The Federal Reserve issued a new series of US $\$ 100$ notes in October 2013 , and thus, the estimate is as of 2012, as not enough data were available at the time of estimation. 
next paragraph might not be applicable to all countries, particularly those adopting the privatised supply chain approach.

The lifecycle as described by the European Central Bank (ECB) Deinhammer \& Ladi (2017) is shown in Figure 2 . Based on demand forecasts, the required banknotes are printed at the factory from where they are then delivered to CBs. The CB distributes the banknotes to the wholesale cash industry, known as cash handlers (CHs), such as cash in-transit companies (CITs). These in turn deliver banknotes to retailers, building societies, commercial banks, and automated teller machines (ATMs), from where the public receives cash. When there is an excess number of banknotes in circulation, they are either stored or taken by CITs. CITs deliver the excess banknotes to the $\mathrm{CB}$, banks, or $\mathrm{CHs}$ for quality checks or to $\mathrm{CHs}$ for recirculation. When banknotes are returned to the $\mathrm{CB}$, they go through a quality check process by sorting machines in which they are either destroyed because they are not of a certain quality level or returned for recirculation (Deinhammer \& Ladi, 2017). The machines also perform authenticity tests, whereby counterfeit banknotes are not destroyed, but instead are sent to the police for inspection (Wettstein et al., 2000). During this process, some banknotes are either exported from the country or imported from other countries. This occurs via both $\mathrm{CHs}$ and the public that travels abroad.

\section{[Figure 2 about here]}

Accurate prediction of the lifetime of banknotes is of vital importance for issuers of banknotes. Under-estimation can result in excess banknotes having to be printed, which is unnecessarily costly, as well as lead to storage costs. On the contrary, overestimation leads to a point at which the issuer is unable to meet the public's demand for banknotes. This may result in cash cycle problems, such as lower quality in circulation, because banks may need to provide customers with unfit banknotes if they run out of fit ones. However, with collection of data becoming an easier task for banknote issuers, the estimates of banknote lifetime are becoming more accurate with time.

This study seeks to provide banknote printing companies, CBs or any organsiations managing banknote with a tool that can be applied to cash cycles of different countries to understand the deterioration process of banknotes. The aim is to develop a model that uses discrete states of the fitness levels of banknotes, as this approach has never been used in the past. These organisations could employ the model to forecast banknote quality in circulation. In addition, the developed tool could be easily manipulated, allowing for precise suggestions on potential improvements to real cash cycles. To the best of our knowledge, this study is the first to apply a semi-Markov model to estimate the lifetime of banknotes. Although some R packages with functions for semiMarkov models exist (e.g. Barbu et al. (2018); Listwon \& Saint-Pierre (2015)), we have built a model in $\mathrm{R}$ that does not depend on pre-existing packages ${ }^{3}$. The model and it's functions are built in away that works best for modeling the lifetime of banknotes.

\section{Literature Review}

One of the simplest methods used by currency issuers for estimating banknote lifetime is the steady-state method, also known as the turnover method. Its name denotes the idea that after a series of banknotes has been in the circulation for a number of years, the banknotes' shredding rate reaches a steady level. This method uses the average

${ }^{3}$ Details of these $\mathrm{R}$ codes and explanations are provided in the supplementary materials. 
number of banknotes in issue and the total number of banknotes destroyed within a year to estimate the average banknote life. It simply measures the average number of years required to destroy all the banknotes currently in circulation if the current rate of shredding remains the same (Rush et al., 2015). A limitation of this method is that it is influenced by new banknotes issued within a year. The average number of banknotes in issue reflects the cumulative sum over a number of years, including the year of estimation. Meanwhile, destroyed banknotes usually include only banknotes that have been in circulation for a reasonable amount of time. To overcome the limitation of the steady-state method, Feige (1989) proposed an alternative method for calculating banknote lifetime, the Eurosystem formula, which is based on the mean lifetime number of transactions divided by mean yearly number of transactions. Both of the above mentioned methods are simple to understand and easy to calculate. However, they pose some limitations. Firstly, both models assume a constant probability of becoming unfit, which is not quite realistic. Secondly, neither of the models allows change of policies by currency issuers, which in the real world occurs quite often. Thirdly, neither of the models can account for any sudden changes in banknote demand.

To overcome these limitations, the Reserve Bank of Australia proposed a new method to estimate the banknote lifetime (Rush et al., 2015). The method uses survival analysis, which is a widely employed tool in various application areas, to estimate different probabilities of a banknote's survival and the number of banknotes based on specific issues that are expected to last over time. By exploring different functions, Rush et al. (2015) found that the survival function of banknote lifetime is good to describe by a Weibull distribution. The advantage of the survival model is that it can include explanatory variables to capture some special events, such as a cohort with new design leads to different aging speed, and a certain year with higher demand for banknotes. However, it does not provide a clear mechanism for a CB to change its sorting policy, namely, frequency and volume of sorting over time.

There is a collection of studies related to the production of banknotes (Fase, 1981; Hatzakis et al., 2010; Massoud , 2005). Some of them have analysed general demand for banknotes, the physical distribution of banknotes, and the logistics of moving banknotes among banks and financial institutions. Not many of them have captured the importance of sorting. Fase et al. (1979) is one of the few studies that includes the sorting process and the fact that a certain percentage of sorted banknotes is returned for circulation. However, the model does not look at different aging speed of banknotes.

In 2017, the ECB published a paper which detailed two models used for the simulation of banknote cash cycles (Deinhammer \& Ladi, 2017). The two models had different simulation approaches. Unlike some previous works, these models have covered a number of key banknote events, such as ageing, sorting accuracies, inflow/outflow to other countries, and production variations. The first model is called a theoretical model-specific concept, as the distribution of different events is mainly based on the literature or the ECB's previous studies. For example, the model could fit various distribution functions to represent banknote ageing. The range of distribution functions (e.g. Gamma, Poisson, Weibull, etc.) used in the study were proposed by other CB studies (Den Butter \& Coenen , 1982; Gillieson , 1977). The second model proposed by the ECB used real data, collected via an external circulation trial which ran for 2 years in Austria, Ireland, and the Netherlands, to simulate the cash cycles of specific countries. In each of the countries, 5 banknotes were issued with registered serial numbers. The data collection involved logging the time of return, the soil level, and a range of defect parameters together with whether the banknote was sorted as fit or unfit (Deinhammer \& Ladi, 2017). The advantage of the second model is essentially 
that it does not need to rely on estimates. However, it may be challenging to collect some data, such as inflows/outflows of banknotes from a country.

The models of the ECB have made a large contribution to the literature on banknote modelling and are a major source of inspiration for the model developed for this study, particularly for their theoretical model-specific concept. One of the assumptions of the ECB model is that banknotes at all fitness levels have the same aging speed. This may be true, but if a model could allow the use of different aging speeds in different fitness states, users would be able to adjust the model to their own country's circumstance. Another limitation of the ECB model is that it allows printing of banknotes only at the time of inspection and thus, it does not give the user the flexibility to print banknotes at any time throughout the simulation period. Table 2 provides an overview of the properties of key models used for banknote lifetime modelling.

In this study, we propose the use of semi-Markov models to capture the deteriorating process of banknotes and use it as a base to estimate the fitness levels of banknotes in circulation. Since the 1950s, semi-Markov models have been used in various applications (Barbu \& Limnios (2009); Black et al. (2005); Uhry et al. (2010); Votsi et al. (2018)). The advantage of semi-Markov models is that users can choose a distribution to represent the sojourn time in a state and can have a transition probability to model the movement among states. Thus, the aging of banknotes can be modelled by the former and the defect incidents can be modelled by the latter. Essentially, the semi-Markov model allows users to choose different distributions and different input parameters for different states. Simulations can then be conducted using the semiMarkov model as a basis for estimating the movement of banknotes. In the simulation model, parameters related to the inspection policy (e.g. volume and frequency) can then be included.

[Table 2 about here]

\section{The Model}

In this section, we are going to introduce our model which is similar to those presented in Foucher et al. (2005) and Votsi et al. (2012). Let $S=\{1,2, \ldots, s\}$ be a finite state space representing the fitness level of a banknote. A Markov Renewal Process (MRP), $(X, T)=\left(X_{n}, T_{n}\right)_{n \geq 0}$, is defined on a complete probability space, where $\left(X_{n}\right)_{n \geq 0}$ forms an embedded Markov chain (EMC) with values defined on $S$ and $\left(T_{n}\right)_{n \geq 0}$ are the jump times. The sojourn times $J_{0}=T_{0}=0, J_{1}, J_{2}, \ldots$ in $\left(X_{n}\right)_{n \geq 0}$ are defined by $J_{n}=T_{n}-T_{n-1}$. Define also the semi-Markov process (SMP) $Z_{t}=X_{N(t)}, \forall t \geq 0$ where $N(t)$ is the counting process of the SMP up to time $t$. The semi-Markov kernel of the SMP is defined as

$$
Q_{i j}(x)=P\left(X_{n+1}=j, J_{n+1} \leq x, \mid X_{0}, X_{1}, \ldots, X_{n}=i, J_{0}, J_{1}, \ldots, J_{n}\right)
$$

for all $x \in \mathbf{R}^{+}$and $i, j \in S$. The transition probabilities of the EMC, $\left(X_{n}\right)_{n \geq 0}$, are defined as $p_{i j}=\lim _{t \rightarrow 0} Q_{i j}(t)$. As it is generally uncommon for CBs to attempt cleaning of banknotes (i.e. removing their soil and making them more fit), transitions to lower indexed states are not allowed in this study. Thus, the transition probability matrix $P$ has the following form: 


$$
P=\left[\begin{array}{ccccc}
0 & p_{12} & p_{13} & p_{14} & p_{15} \\
0 & 0 & p_{23} & p_{24} & p_{25} \\
0 & 0 & 0 & p_{34} & p_{35} \\
0 & 0 & 0 & 0 & p_{45} \\
0 & 0 & 0 & 0 & p_{55}
\end{array}\right]
$$

The cumulative distribution functions of the holding times in state $i$ before going to state $j$ can be defined as

$$
F_{i j}(x)=P\left(J_{n+1} \leq x \mid X_{n}=i, X_{n+1}=j\right)=\int_{0}^{x} f_{i j}\left(z, \theta_{i j}\right) d z .
$$

where $f_{i j}\left(x, \theta_{i j}\right)$ for $i, j \in S$ is the probability distribution function, $t \in[0, \infty)$ with $\theta_{i j}$ is the parameter vector of the density function representing the transition between $i$ and $j$, and $n \geq 0$. Different distribution functions and parameters could be used between different transitions. In the next section, we will provide more information about the choice of distribution functions and the corresponding parameters in modelling the lifetime of banknotes.

In this paper, we use $s=5$ where state 1 represents Very Fit and state 5 represents Very Unfit. The five fitness stages of structural deterioration are considered acceptable by the Euro system (Deinhammer \& Ladi, 2017) and thus, no more are added to the model. Essentially though, if the user would like to have a more refined definition on banknote fitness, they can change the number of fitness levels into more states (e.g. 10 or 100). The concept presented below will still be applicable. The five states are split into two categories. Three of them (i.e. state 1 to 3 ) represent fit banknotes, meaning that any banknotes in those states are accepted and retained in circulation by sorting machines. Any banknotes in the last two states are unsuitable for recirculation and thus, are destroyed by sorting machines. This grouping of fit and unfit banknotes can be changed by CBs or CHs.

All newly printed banknotes begin in state 1 and can move to other states according to their deterioration process. In the case in which the banknote deteriorates only due to natural effects, such as soiling, the deterioration follows a Markov process with sequential structure. The banknote goes through all the deterioration stages before reaching the final absorbing state. However, in real life, banknotes are exposed to random events and can move to a higher state (i.e. less fit). For example, a brand new banknote in state 1 can jump to state 5 when graffiti is drawn on it. Figure 3 shows all possible transitions that a banknote can make. This means different banknotes could stay in a fitness state for a different duration of time.

Note that state $s$ (i.e. state 5 for this paper) is an absorbing state and its holding time distribution is undefined. In the model of Figure 3, the definition of the states can be considered to adhere to the defects, as shown in Table 3. Most of the defects are allowed in more than one state, because sorting machines can determine the level of the defect, thereby assigning it to the appropriate deterioration state. For example, a banknote with graffiti covering most of the area is considered to be in state 5 but one that has only a small mark of graffiti is considered to be in state 4 .

[Figure 3 and Table 3 about here] 


\section{Experimental Results}

The model is implemented in the statistical software package R. In this section, we first present results from the basic model where the sojourn time distributions and their parameters are explored to check how these affect the progress of banknotes to different states. Section 4.2 presents results obtained from running the full model which includes a few more parameters and functions. Results of a sensitivity analysis conducted with the full model will be presented at the end of this section.

\subsection{Basic Model}

In this subsection, the results of the basic model are presented. The parameters corresponding to the basic model are shown in Table 4 . Below information explain the assumptions and the corresponding input parameters:

- All banknotes are printed at time 0. In other words, all of them begin in state 1. Thus, initial distribution is $\left[\begin{array}{lllll}1 & 0 & 0 & 0 & 0\end{array}\right]^{T}$.

- Banknotes deteriorate only due to natural defects and thus, pass from all states until reaching the final state. Thus, transition probabilities $p_{12}=p_{23}=p_{34}=$ $p_{45}=p_{55}=1$ and $p_{i j}=0$ for other $i, j$.

- The banknotes modelled have an average lifetime of 90 months, that is, to move from state 1 to state 4 . This can be thought of as a banknote of medium denomination (e.g. €20).

- Banknotes spend roughly the same time in all fit states. Thus, banknotes spend on average 30 months in each fit state.

- Transitions between unfit states is faster than that between fit states, as, in general, people tend to treat unfit banknotes with less care. It takes them approximately 20 more months to move from state 4 to the final absorbing state. This and the previous bullet points explain Parameter 1.

- The basic model has been tested with four different distributions: Poisson, Exponential, Gamma and Weibull. As the failure rate of banknotes increases with time, the shape parameters of Weibull and Gamma are greater than 1.

- The simulation time is 180 months.

- The number of initial banknotes is 10,000 .

[Table 4 and Figure 4 about here]

The results of the basic model using the four different distributions are displayed in Figure 4. All four plots of Figure 4 show that by the end of the simulation, most or all of the 10,000 banknotes printed at time 0 are very unfit. This is because the simulation period is 15 years, whereas the average lifetime of banknotes is 90 months (i.e. 7.5 years). This highlights the importance of extra printing sessions for cash cycles as well as the inspection of banknotes for the removal of unfit ones. Figure 4 also shows that even when the same parameters are used, different sojourn time distributions give considerably different probability distributions. Hence, it is imperative for distributions to be fitted correctly so that the model gives as accurate simulations as possible. In this study, we follow the suggestion of Rush et al. (2015) who find that Weibull distribution is suitable for describing the ageing process of banknotes. Thus, in the rest of the analysis, only the Weibull distribution is used as sojourn time distribution.

[Figure 5 about here] 
Figure 5 shows how the progress of banknotes through different states is affected by using different shape parameters for the Weibull sojourn time distributions. As the probability of banknotes transiting to higher indexed states increases with time, the shape parameter in banknote modelling is always greater than one. Figure 5 also shows that using a lower shape parameter, banknotes issued at the same time can progress differently. For example, comparing the distribution in month 50, for shape parameter equals to 1.5, there will be less than $10 \%$ in state $1,40 \%$ in state $2,30 \%$ in state 3 and the rest in state 4 or 5 . However, if the shape parameter is 4.5 , none of these banknotes will still stay in state 1 but they will either be in state 2 or 3 . For this study, we assume shape parameter equals to 1.5 as we would like to observe banknotes with various soiling speeds. In practice, users could change this shape parameter based on their individual country's circumstance.

\subsection{Full Model}

In this subsection, the full model is first applied to four theoretical cash cycles to obtain the probability distributions of the different states of banknotes. The four cash cycles differ in their probabilities and initial distributions. In case 1 (which is the same as the basic model) and case 2, banknotes deteriorate only due to soiling and all of them begin in state 1 , as in the case of the basic scenario. However, there is an initial non-zero probability for all states in case 2 .

In case 3 , all banknotes are new at the beginning of the simulation, but they can directly move to any higher indexed state. We choose the parameters such that majority of them move to the next state. For example, for banknotes in state 1, the transition probabilities are $p_{12}=.80, p_{13}=.10, p_{14}=.06, p_{15}=.04$. In other words, $20 \%$ of these banknotes would experience an event (i.e. examples listed in Table 3 to speed up their aging process. Once they have directly moved to a higher indexed state, we assume these banknotes will age faster. For example, for banknotes moving from state 1 to 3 and then to 4 , it takes them $25+35=60$ months to move to an unfit state. For these banknotes, we also assume slightly lower shape parameters (i.e. 1.3 or 1). The idea is to assume a more diverse soiling speed among these banknotes. In case 4 , there are banknotes in all states at the beginning of the simulation and there is again a transition probability to all higher indexed states. For cases 3 and 4, the shape parameter for transitions to states 4 and 5 are set equal to 1 , as it is assumed that the failure rate to those states is constant with time. This is because the events causing banknotes to jump to those states are random.

All input parameters are presented in Table 4 . The other parameters (e.g. inspection frequency, proportion of false fit, etc.) were chosen by using (1) similar parameters as those of Deinhammer \& Ladi (2017) or (2) the suggestions from De La Rue Analytics. As mentioned, users could change these parameters based on their individual country's policies.

\section{[Figure 6 about here]}

In Figure 6 , the effect of both inspection and new prints can be observed. These are represented by the sudden increase in the probability of banknotes being very fit at those times. The effect of printing new banknotes is observed to decrease with time. This is because a fixed number of banknotes is printed every year and the impact that the 1,000 newly printed banknotes have on the probabilities decreases as the total volume in circulation increases. At inspection times, the increase in probability 
of banknotes being very fit is equivalent to the decrease in that of being in the two unfit states. Furthermore, it is clear that the results change considerably when all the defects are considered by the model. This is demonstrated by the difference between case 1 and case 3 and that between case 2 and case 4 .

\subsubsection{Sensitivity analysis of the full model}

One of the main objectives of the full model is to determine what percentage of banknotes is in unfit states at the end of the simulation. To check how the different parameters affect this percentage, a sensitivity analysis on the input parameters of case 4 is performed. The parameters that have no impact on the probabilities or that are assumed to be fixed (e.g. number of initial banknotes) are not considered in this subsection. Those that affect the progress of banknotes to different states are adjusted to two different values from the one used in the base case, to record the change in the proportion of unfit banknotes at the end of the simulation. A summary of the parameters changed and the impact these have on the percentage of unfit banknotes at the end of the simulation is presented in Table 5 . A plus or minus $20 \%$ of those numerical entries is used to test different scenarios such as more or less banknotes printed in each printing session.

[Table 5 about here]

The results presented in Table 5 show that all of the parameters affect the proportion of unfit banknotes to some extent. The two parameters that have the greatest impact are the number of banknotes inspected and the inspection frequency. An increase of $20 \%$ in the number of banknotes inspected each time decreases the proportion of unfit banknotes at the end of simulation by almost $5 \%$. This is reasonable, as the more banknotes are inspected, the more unfit banknotes are replaced with new ones, thereby decreasing the percentage of unfit banknotes in circulation. Another conclusion is that the frequency at which inspections occur impacts the results. Inspecting banknotes every 4 months instead of every 6 months decreases the unfit banknotes by $10 \%$. This is a reasonably large impact for the quality of banknotes in circulation.

\section{Conclusion and Recommendations}

This study aims to build a mathematical model that can represent the deterioration progress of banknotes using discrete states. Our proposed model has some advantages over previous models. First, we use a discrete semi-Markov chain to simulate cash cycles. Because the transition of a banknote to another state depends on the time it has spent in the current state and not how long in total it has been in circulation, a semi-Markov model is more suitable than the models proposed by other researchers. By estimating the parameters of a cash cycle using an already existing model built by De La Rue Analytics, the semi-Markov model can be a useful tool for banknote printing companies as well as CBs. It can simulate both theoretical and real cash cycles by taking into account features of the cash cycle, such as sorting and printing frequencies. The model gives the user the flexibility to consider any number of possible states and to modify the minimum unfit state to change the threshold of sorting. The model also considers the inaccuracies of sorting machines to provide more accurate results. The discrete state model can be applied to cash cycles of different countries which may have completely different characteristics to each other. It can forecast 
the number of banknotes in each of the states and thus, allows conclusions to be drawn about the quality of banknotes in circulation. It can also be used to review how changing some of the parameters of a cash cycle, such as sorting frequency, can impact the quality of banknotes in circulation. We also conduct a sensitivity analysis to check which parameters have the greatest impact on the percentage of unfit banknotes in circulation. These parameters are found to be sorting frequency and the sorting volume of banknotes. Similar sensitivity analysis can be completed for real cash cycles to check what changes can be made to improve banknote quality in the future.

A few recommendations are provided to make the simulations of the banknote model more realistic and to produce more accurate results. One of the factors affecting the cash cycle of a country is the number of banknotes that enter and leave the country. These banknotes are not considered in the model. Introducing extra parameters that account for these banknotes would make the simulations more realistic. There are models that can estimate the number of banknotes that leave a country (Bartzsch et al. , 2013). Including parameters in the model to represent the inflows and outflows of banknotes of a country in each state would have an impact on the results of the probability plots. To account for the inaccuracies of sorting machines, this study uses two parameters to represent the percentage of false fit and false unfit banknotes. In other words, the model uses the same probability for all fit and all unfit states. An improvement to this feature would be to allow a vector of probabilities and thus, have a different probability of false sorting for each state. This would make the model more realistic, as the probability that the sorting machine falsely sorts a banknote in state 3 as unfit is greater than that of falsely sorting a banknote in state 1 as unfit. A simple expansion to the model developed would involve different denominations. At present, the model allows only input parameters for one denomination or average parameters for all denominations. A model that could simulate the progress of banknotes simultaneously for different denominations would be more beneficial for CBs, as they would be able to consider the overall quality of banknotes in circulation.

\section{References}

Barbu, V.S., Brard, C, Cellier, D., Sautreuil, M., Vergne, N. (2018). SMM: An R package for estimation and simulation of discrete-time semi-Markov models. The $R$ Journal. 10, 226-247.

Barbu, V.S. and Limnios, N. (2009). Semi-Markov chains and hidden semi-Markov models toward applications. New York: Springer-Verlag

Bartzsch, N., Rősl, G., Seitz, F. (2013). Currency movements within and outside a currency union: The case of Germany and the Euro area. The Quarterly Review of Economics and Finance. 53,393-401.

Black, M., Brint, A.T., Brailsford, J.R. (2005). A semi-Markov approach for modelling asset deterioration.Journal of Operational Research Society. 56, 1241-1249.

Cabrero, A., Camba-Mendez, G., Hirsch, A., Nieto, F. (2009). Modelling the daily banknotes in circulation in the context of the liquidity management of the European Central Bank. Journal of Forecasting. 28, 194-217.

Deinhammer, H. and Ladi, A. (2017). Occasional paper: Modelling euro banknote quality in circulation. European Central Bank. 204.

Den Butter, F.A.G. and Coenen, R.L. (1982). The process of soiling and the life of bank notes in the Netherlands. Applied Statistics. 31,226-237.

DLR Analytics. (2018). Whats happening to the volume and value of cash in circulation Retrieved from https://cdn2.hubspot.net/hubfs/2752422/De $\% 20 \mathrm{La} \backslash \% 20 \mathrm{Rue} \backslash \% 2 \mathrm{Feb} \backslash$ $\% 202017 /$ Images/Cash $\ \% 20 i \backslash$ \} \backslash \% 2 0 \text { Circulation.pdf } 
Fase, M.M.G. (1981). Forecasting the demand for banknotes: some empirical results for the Netherlands. European Journal of Operational Research. 6, 269-278.

Fase, M.M.G., van der Hoeven, D., van Nieuwkerk, M. (1979). A numerical planning model for a central bank's bank notes operations. Statistica Neerlandica. 33, 7-25.

Federal Reserve Bank. (2017). How long is the lifespan of U.S. paper money?. Retrieved from https://www.federalreserve.gov/faqs/how-long-is-the-life-span-of-us-paper-money.htm

Feige, E. (1989). Currency velocity and cash payments in the US economy: the currency enigma. University of Wisconsin-Madison.

Foucher, Y., Mathieu, E., Saint-Pierre, P., Durand, J-F., Daurs, J-P. (2005). A semi-Markov model based on generalized Weibull distribution with an illustration for HIV disease. Biometrical Journal. 47, 825-833.

Geismar, H.N. and Sriskandarajah, C. and Zhu, Y. (2017). A review of operational issues in managing physical currency supply chains. Production and Operations Management. 26, 976-996.

Gillieson, A.H. (1977). Research into the extension of the life of banknotes: Results of 1973, 1975 and 1976 field trials. Bank of Canada Technical Report. 10.

Hatzakis, E., Nair, S.K., Pinedo, M.L. (2010). Operations in financial services - an overview. Production and Operations Management. 19, 633-664.

Lepecq, G. (2016). Cash Essentials: Beyond Payments. AGIS Consulting.

Listwon, A. \& Saint-Pierre, P. (2015). SemiMarkov: A R package for parametric estimation in multi-state semi-Markov models. Journal of Statistical Software. 66, 784.

Massoud, N. (2005). How should central banks determine and control their bank note inventory. Journal of Banking 83 Finance. 29, 3099-3119.

OBrien, S. (2017). Understanding Consumer Cash Use: Preliminary Findings from the 2016 Diary of Consumer Payment Choice. Federal Reserve Bank of San Francisco. Retrieved from https://www.frbservices.org/news/fed360/issues/010218/ 010218-cash-2016-diary-consumer-payment-choice.html

Rush, Alexandra and others. (2015) Research discussion paper: The Life of Australian Banknotes. Reserve Bank of Australia. RDP 2015-10.

Uhry, Z., Hdelin, G., Colonna, M., Asselain, B., Arveux, P., Rogel, A., Exbrayat, C., Guldenfels, C., Courtial, I., Soler-Michel, P., Molini, F., Eilstein, D., Duffy, S.W. (2010). Multi-state Markov models in cancer screening evaluation: a brief review and case study. Statistical Methods in Medical Research. 19(5), 463-486.

United Nationals-Treasury. (2019). United Nationals operational rates of exchange Retrieved from https://treasury.un.org/operationalrates/OperationalRates.php

Votsi, I., Limnios, N., Papadimitriou, E., Tsaklidis, G. (2018). Earthquake statistical analysis through multistate modeling. Wiley

Votsi, I., Limnios, N., Tsaklidis, G., Papadimitriou, E. (2012). Estimation of the expected number of earthquake occurrences based on semi-Markov models. Methodology and Computing in Applied Probability. 14(3), 685-703.

Wettstein, F., Lieb, H., Lieb, H. (2000). Quarterly Bulletin: Life cycle assessment (LCA) of Swiss banknotes. Swiss National Bank. Retrieved from https://www.snb.ch/en/mmr/ reference/life_cycle_banknotes/source/life_cycle_banknotes.en.pdf 
Denomination Average Lifetime (Years)

$\$ 1$

5.8

$\$ 5$

5.5

$\$ 10$

4.5

$\$ 20$

7.9

$\$ 50$

8.5

$\$ 100$

15.0

Table 1. Average lifetime of US banknotes. 


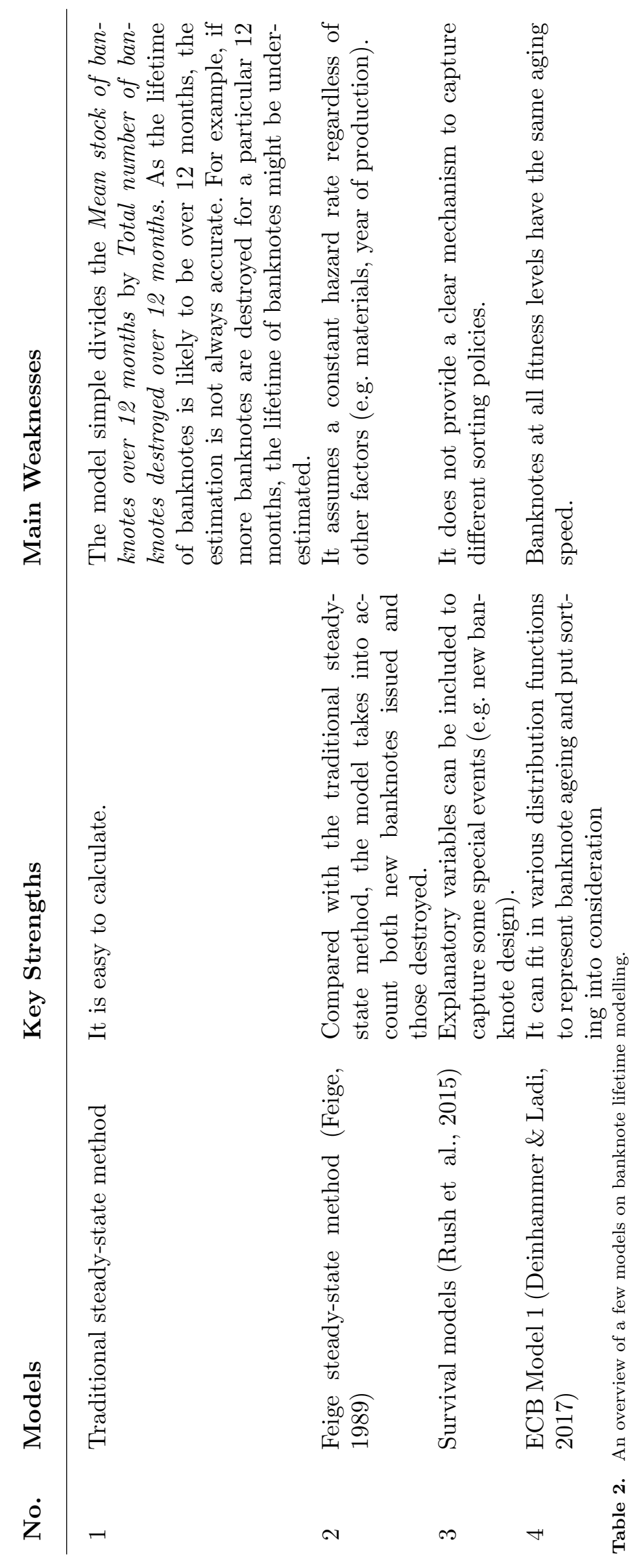




\begin{tabular}{lccccc} 
Defect & State 1 & State 2 & State 3 & State 4 & State 5 \\
\hline Crumples & $\checkmark$ & $\checkmark$ & $\checkmark$ & $\checkmark$ \\
Folded Corners & & $\checkmark$ & $\checkmark$ & $\checkmark$ & $\checkmark$ \\
Fold & $\checkmark$ & $\checkmark$ & $\checkmark$ & $\checkmark$ \\
Soil (paper) & & & $\checkmark$ & $\checkmark$ & $\checkmark$ \\
Inkwear (polymer) & & $\checkmark$ & $\checkmark$ & $\checkmark$ \\
Limpness & & $\checkmark$ & $\checkmark$ & $\checkmark$ \\
Stains & & & $\checkmark$ & $\checkmark$ \\
Mutilation & & & $\checkmark$ & $\checkmark$ \\
Tears & & & $\checkmark$ & $\checkmark$ \\
Hole & & & $\checkmark$ & $\checkmark$ \\
Repair & & & $\checkmark$ & $\checkmark$ \\
Graffiti & & & $\checkmark$ & $\checkmark$ \\
3.Derts
\end{tabular}

Table 3. Defects observed in each state. 


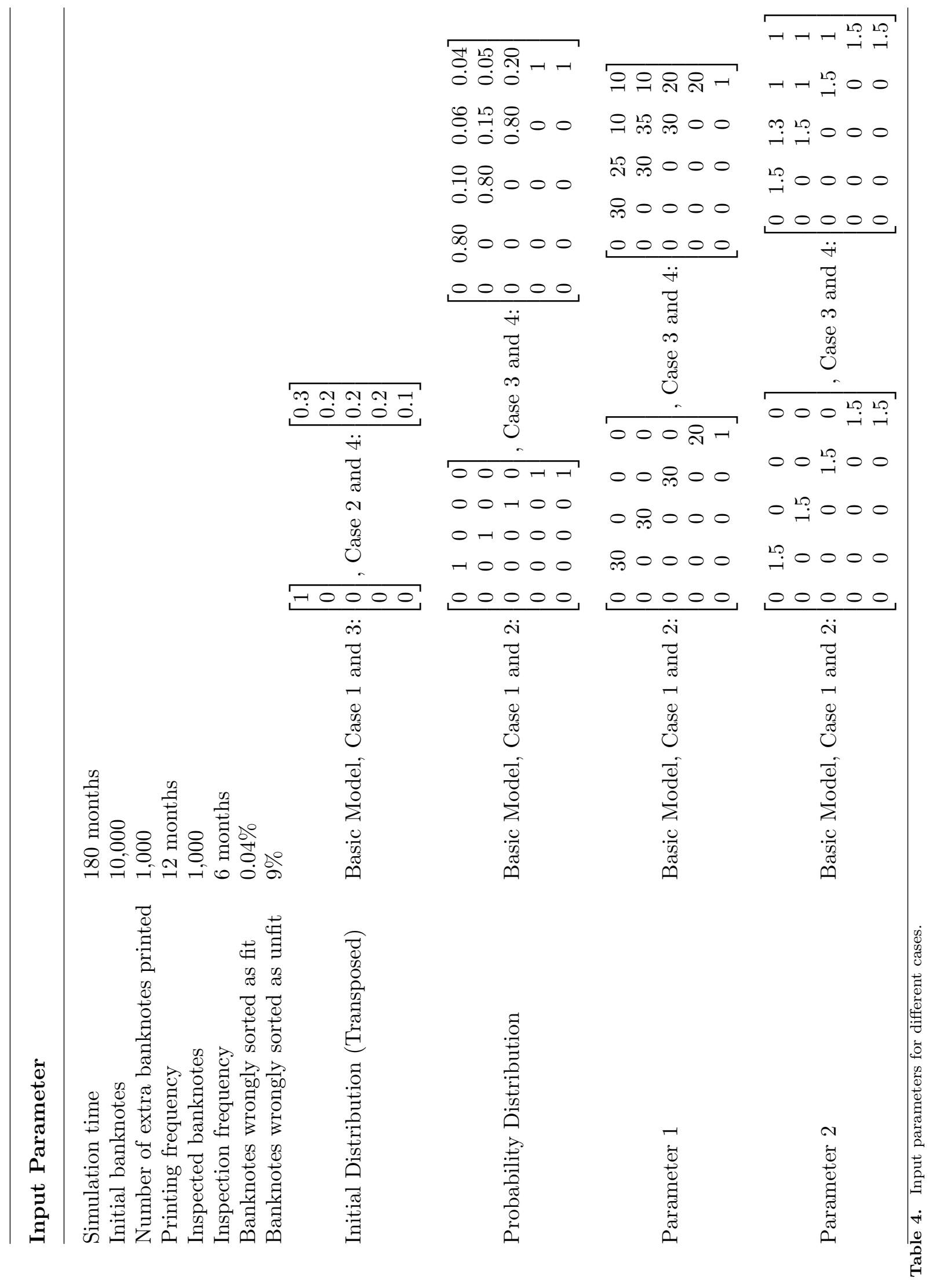




\begin{tabular}{|c|c|c|c|c|}
\hline & & & $\begin{array}{l}\text { Proportion of unfit } \\
\text { banknotes at the } \\
\text { end of simulation }\end{array}$ & $\begin{array}{l}\text { Percentage change } \\
\text { from base case }\end{array}$ \\
\hline \multicolumn{3}{|l|}{ Case 4} & \multicolumn{2}{|l|}{0.6064} \\
\hline Input Parameter & Case 4 Value & Scenario Value & & \\
\hline \multirow{2}{*}{ Extra banknotes printed } & \multirow{2}{*}{1000} & 800 & 0.4638 & $-2.3061 \%$ \\
\hline & & 1200 & 0.4806 & $1.2401 \%$ \\
\hline \multirow{2}{*}{ Printing frequency } & \multirow{2}{*}{12 months } & 6 months & 0.4983 & $4.9619 \%$ \\
\hline & & 18 months & 0.4515 & $-4.8913 \%$ \\
\hline \multirow{2}{*}{ Inspected banknotes } & \multirow{2}{*}{1000} & 800 & 0.5056 & $6.5133 \%$ \\
\hline & & 1200 & 0.4403 & $-7.2464 \%$ \\
\hline \multirow{2}{*}{ Inspection frequency } & \multirow{2}{*}{6 months } & 4 months & 0.4017 & $-15.3775 \%$ \\
\hline & & 8 months & 0.506 & $6.5807 \%$ \\
\hline \multirow{2}{*}{ Proportion of false fit } & \multirow{2}{*}{0.004} & 0.0032 & 0.4766 & $0.4044 \%$ \\
\hline & & 0.0048 & 0.4707 & $-0.8426 \%$ \\
\hline \multirow{2}{*}{ Proportion of false unfit } & \multirow{2}{*}{0.09} & 0.072 & 0.4739 & $-0.1685 \%$ \\
\hline & & 0.098 & 0.4745 & $-0.0506 \%$ \\
\hline \multirow{2}{*}{ Average lifetime } & \multirow{2}{*}{90} & 72 & 0.5096 & $7.3559 \%$ \\
\hline & & 108 & 0.4508 & $-5.0472 \%$ \\
\hline
\end{tabular}

Table 5. Sensitivity analysis of full model. 